\title{
Scleromyxedema with Subcutaneous Nodules: Successful Treatment with Thalidomide and Intravenous Immunoglobulin
}

\author{
M. Dolenc-Voljča,d $\quad$ V. Jurčićc A. Hočevar ${ }^{b} \quad$ M. Tomšičb, d
}

Departments of ${ }^{\mathrm{a}}$ Dermatovenereology and ${ }^{\mathrm{b}}$ Rheumatology, University Medical Centre Ljubljana, 'Institute of Pathology, Faculty of Medicine, and ${ }^{d}$ Faculty of Medicine, University of Ljubljana, Ljubljana, Slovenia

\section{Key Words}

Scleromyxedema · Mucinosis · Papular mucinosis · Nodular mucinosis · Monoclonal gammopathy $\cdot$ Intravenous immunoglobulin $\cdot$ Thalidomide

\begin{abstract}
Scleromyxedema is a rare cutaneous mucinosis, usually presenting with generalized papular eruption and sclerodermoid induration, monoclonal gammopathy and systemic manifestations. An atypical clinical presentation with cutaneous and subcutaneous nodules has been reported rarely. In recent years, intravenous immunoglobulin (IVIg) appears to be the therapy of choice for scleromyxedema. Treatment experiences in atypical manifestations with mucinous nodules are limited to sporadic reports. We report the case of male patient with atypical scleromyxedema without underlying paraproteinemia, presenting with generalized papular and sclerodermoid skin eruption and multiple nodular mucinous lesions on the fingers and face as well as on the eyelids, and associated systemic symptoms. Complete regression of all cutaneous lesions and extracutaneous symptoms with sustained remission was achieved by combined treatment with thalidomide and IVIg.
\end{abstract}

(C) 2013 S. Karger AG, Basel

\section{Introduction}

Scleromyxedema is a rare and distinctive variant of cutaneous mucinosis of unknown etiopathogenesis. Diagnostic criteria include generalized papular and sclerodermoid 
Dolenc-Voljč et al.: Scleromyxedema with Subcutaneous Nodules: Successful Treatment with Thalidomide and Intravenous Immunoglobulin

eruption, mucin deposition with fibroblast proliferation, monoclonal gammopathy and the absence of thyroid disease [1]. It usually appears in middle and older age, without gender predilection.

Skin lesions are characterized by multiple firm waxy papules, often in a linear arrangement. Erythema and edema, infiltrated plaques, diffuse sclerodermoid induration, acrosclerosis, leonine facies and alopecia may also occur $[2,3]$. Deposition of mucin in nodular lesions is very rare and has been only sporadically reported [4-6]. Involvement of the periorbital region with mucinous nodules has been reported even more rarely [5]. In addition to cutaneous manifestations, extracutaneous involvement is present in the majority of patients, and is associated with severe morbidity and increased mortality [2, 3, 7].

A variety of different therapeutic approaches for dealing with this chronic and progressive mucin deposition disorder have been used. Compared to older drugs, intravenous immunoglobulin (IVIg) has shown excellent results with a good safety profile [8]. There have been only sporadic reports of treatment experiences for nodular mucinous skin involvement.

\section{Case Report}

A 42-year-old male had been well until December 2008, when he noted progressive swelling of the face, hands and forearms, accompanied by pruritus, increased hair loss, arthralgia, myalgia and fatigue. In the following weeks, skin induration of the hands and forearms, papular eruption on the neck and upper trunk, and nodular lesions on the face and fingers developed. The patient was admitted to the local hospital, where systemic fibrosing disorder was suspected and systemic glucocorticoid treatment (methylprednisolone 1 $\mathrm{mg} / \mathrm{kg}$ body weight) was introduced. Since only partial regression of the facial and hand edemas was observed, he was referred to the University Medical Centre Ljubljana, initially to the Department of Rheumatology and later to the Department of Dermatovenereology.

At admission in February 2009, dense papular lesions were present on the neck, retroauricular areas, scalp and upper trunk, partly in a linear arrangement. Sclerodactyly with impaired finger motility was present. Tender nodules of a hard consistency could be palpated bilaterally on the upper and lower eyelids, on the forehead, lateral parts of the nose, behind the ears and on the fingers (fig. 1). Sclerodermoid induration of the skin with irregular loss of hair was present on the forearms. The patient still complained of general symptoms and dysphagia.

Complete blood cell count, serum levels of inflammatory parameters, electrolytes, glucose, calcium, creatinine kinase, myoglobin, aldolase as well as tumor markers were within normal range. Renal function tests and urinalysis were normal. Testing for antitopoisomerase and anticentromeric antibodies, antiphospholipid antibodies and cryoglobulins was negative. Thyroid function was normal. Serum protein electrophoresis showed polyclonal hypergammaglobulinemia without paraproteinemia. In addition, immunofixation electrophoresis of serum and urine did not show monoclonal paraproteinemia.

Chest radiograph was normal, as were the results of lung function tests, abdominal ultrasound, echocardiography, nailfold capillaroscopy, radiographs of the hands and feet and bone marrow examination. Since electromyography detected signs consistent with myopathy, neurological examination and muscle biopsy were performed. The former revealed no pathology but the biopsy demonstrated mild myopathy with atrophy involving selectively type 2 fibers without inflammation. Photoplethysmography did not confirm 
Dolenc-Voljč et al.: Scleromyxedema with Subcutaneous Nodules: Successful Treatment with Thalidomide and Intravenous Immunoglobulin

Raynaud's phenomenon. Computer tomography of the periorbital region excluded involvement of extracutaneous tissue with nodules.

Biopsies of the nodules on the hand and periorbital region and of papular lesions on the trunk were performed. Histopathological examination was characteristic of scleromyxedema in all three specimens. There was abundant proliferation of large stellate fibroblasts in the reticular dermis and subcutis, with prominent deposits of a myxoid substance between thick collagen bundles. Mucin deposition was demonstrated with Alcian blue staining (fig. 2).

According to the clinical picture and histopathology, a diagnosis of scleromyxedema was established. Treatment with thalidomide was introduced (initial dosage $100 \mathrm{mg} /$ day) and the previously prescribed glucocorticoid gradually tapered off and discontinued. After 3 months of thalidomide treatment, only a partial regression of the skin lesions was achieved. Myalgia and arthralgia persisted. Therefore, additional treatment with high-dose IVIg was introduced $(0.4 \mathrm{~g} / \mathrm{kg}$ body weight/day for 5 consecutive days every month for the duration of 6 months). After only two cycles of IVIg, a marked regression of the nodular lesions on the face and hands and improvement of the papular and sclerodermoid mucinosis was observed. The general clinical condition of the patient improved significantly. Thereafter, he received four additional cycles of IVIg at the same dosage at 8-week intervals. Treatment with thalidomide was continued with a lower daily dose (50 mg/day) and finally discontinued in July 2011 due to complete disease remission (fig. 3).

During the 2-year follow-up, the patient sustained a complete drug-free remission. Results for paraproteinemia were negative. During thalidomide treatment, the patient reported numbness in his feet; however, electromyographic investigation did not confirm a peripheral sensory neuropathy.

\section{Discussion}

The patient in our case report presented with an atypical form of scleromyxedema. Three of the four diagnostic criteria of scleromyxedema were fulfilled. Monoclonal gammopathy could not be demonstrated, even though a more sensitive diagnostic method (immunofixation electrophoresis) was performed. According to the recent classification, cases without monoclonal gammopathy are classified under atypical forms [1,2]. Such cases have been reported only rarely [4-6].

The role of monoclonal paraproteins in scleromyxedema is still elusive. It is not clear whether they represent a primary or a secondary phenomenon in the pathogenesis. In clinical observations, paraprotein levels did not correlate with disease severity [7, 9-11]. Monoclonal gammopathy has been found in $88-100 \%$ of patients and has usually been of IgG $\lambda$ light chains $[3,7,9,12]$. Paraproteinemia is generally present at the beginning of disease, though a delayed appearance should also be considered $[1,6,13]$. Other reported associations include biclonal gammopathy $[3,12,14]$.

In our patient, due to sclerodermoid skin lesions on the face, forearms and hands, and initial extracutaneous symptoms, systemic sclerosis was first suspected. Proximal muscle weakness, myositis, polyarthritis and gastrointestinal involvement with dysphagia have been reported in $60-90 \%$ of patients with scleromyxedema $[3,9,12]$ and may be prominent. Cardiovascular, lung, renal, hematological and peripheral and central nervous system disorders have been also reported with different frequencies, ranging from 10 to $60 \%[3,7$, $9,12]$. In such cases, scleroderma represents an important differential diagnosis [12, 15].

Later in the course of the disease, atypical nodular lesions with abundant mucin deposits in the cutis and subcutis developed on the face and fingers, along with typical papular and 
Dolenc-Voljč et al.: Scleromyxedema with Subcutaneous Nodules: Successful Treatment with Thalidomide and Intravenous Immunoglobulin

sclerodermoid eruptions. A nodular form of lichen myxedematosus is a well-established entity among localized mucinoses [2]. In scleromyxedema, nodules have been reported only sporadically, concomitantly with a papular or sclerodermoid pattern of mucinosis $[4-6,16]$, as in our case. Interestingly, in three of these cases monoclonal paraproteinemia could not be demonstrated either [4-6].

Manifestations of scleromyxedema in the ocular region have been found in $24 \%$ of patients, most commonly as thickened skin of the eyebrow and eyelids, palpebral edema, ectropion and lagophthalmos [17]. To our knowledge, skin involvement of the eyelids with mucinous nodules has been reported only once before, with nodules defined as myxomas [5].

Both myxomas and cutaneous focal mucinosis with nodular appearance have been reported in scleromyxedema [4]. Apart from the terminology, we believe that it is important to distinguish lesions in scleromyxedema, which may vary according to the quantity and depth of myxoid tissue, from true neoplasms (cutaneous myxomas as part of the Carney complex and cutaneous angiomyxomas). Cutaneous angiomyxomas are mostly solitary tumors with an additional vascular and sometimes an epithelial component $[18,19]$, both of which were absent in our patient.

The management of scleromyxedema is not well defined. Various therapeutic agents have been used: high-dose corticosteroids, a variety of immunosuppressive and chemotherapeutic drugs, PUVA and UVA1 phototherapy, plasmapheresis, extracorporeal photopheresis, electron beam therapy, $\alpha$-interferon, retinoids, thalidomide, IVIg, bortezomib and autologous stem cell transplantation [1, 3, 9, 15, 20-22]. Treatment with high-dose IVIg has been found to be especially promising in the last decade. Good results have been documented in cases with a papular and sclerodermoid pattern of mucinosis [7-9, 11, 14, 15, 23]. Compared to other treatment options, IVIg has a favorable safety profile. An overview of some novel treatment modalities in scleromyxedema is presented in table 1.

Based on previous reports [10,24, 25], we decided to treat our patient initially with thalidomide. After 3 months, we observed only a moderate improvement of the cutaneous lesions. To improve the treatment response and to avoid potential thalidomide toxicity, especially peripheral sensory neuropathy, we decided on additional treatment with highdose IVIg. For refractory scleromyxedema, IVIg and thalidomide in combination has been suggested as an effective novel treatment option [26]. Both drugs have complex immunomodulatory actions and antifibrotic properties [10, 24, 25]. Their combination probably allows less frequent administration of IVIg and treatment with lower doses of thalidomide.

In contrast to previous reports [7, 9, 23], maintenance infusions of IVIg for a sustained treatment response were not required in our patient. This may be partly due to the combined treatment with thalidomide. The disease duration before treatment introduction probably also has an impact on the further course of the disease. The mean duration of skin disease at diagnosis was found to range from 10 to 12 months $[7,12]$ to several years [3]. Thus, the disease duration of 3 months in the present case was rather short.

Treatment experiences in nodular or other atypical eruptions in scleromyxedema are based on sporadic reports. An unusual nodulocystic form on the face was successfully treated with melphalan [27]. An extensive nodular variant on the face regressed after radiation therapy [16]. In a patient with orbital myxomas, a marked improvement was observed with cyclophosphamide but with serious side effects [5]. In an unusual tumorous variant of scleromyxedema, a highly favorable result was reported with IVIg [13]. In a recent report of disseminated subcutaneous nodules, the patient was treated with low-dose isotretinoin but was lost to follow-up [6]. 
Dolenc-Voljč et al.: Scleromyxedema with Subcutaneous Nodules: Successful Treatment with Thalidomide and Intravenous Immunoglobulin

In conclusion, the present case of scleromyxedema may add new insight into the clinical diversity of this mysterious disease. In an unusual presentation with nodular lesions, including also the periorbital region, successful treatment with a contemporary treatment approach is presented for the first time. Combination of thalidomide and IVIg may be suggested as a good treatment option also in more severe forms of cutaneous mucin deposits in scleromyxedema.

\section{Disclosure Statement}

The authors have no conflicts of interest to disclose.

\section{References}

1 Rongioletti F, Rebora A: Updated classification of papular mucinosis, lichen myxedematosus, and scleromyxedema. J Am Acad Dermatol 2001;44:273-281.

2 Rongioletti F, Rebora A: Mucinoses; in Bolognia JL, Jorizzo JL, Schaffer JV (eds): Dermatology, ed 3. Philadelphia, Elsevier, 2012, pp 687-698.

3 Dinneen AM, Dicken CH: Scleromyxedema. J Am Acad Dermatol 1995;33:37-43.

-4 Rongioletti F, Amantea A, Balus L, Rebora A: Cutaneous focal mucinosis associated with reticular erythematous mucinosis and scleromyxedema. J Am Acad Dermatol 1991;24:656-657.

-5 Craig NM, Putterman AM, Roenigk RK, Wang TD, Roenigk HH: Multiple periorbital cutaneous myxomas progressing to scleromyxedema. J Am Acad Dermatol 1996;34:928-930.

-6 Singh S, Kanwar AJ, Saikia UN: Scleromyxoedema with disseminated subcutaneous nodules: rare presentation of an uncommon dermatosis. Clin Exp Dermatol 2012;38:36-39.

-7 Rongioletti F, Merlo G, Cinotti E, Fausti V, Cozzani E, et al: Scleromyxedema: a multicenter study of characteristics, comorbidities, course, and therapy in 30 patients. J Am Acad Dermatol 2013;69:66-72.

-8 Sroa N, Campbell S, Bechtel M: Intravenous immunoglobulin therapy for scleromyxedema: a case report and review of literature. J Drug Dermatol 2010;9:263-265.

-9 Blum M, Wigley FM, Hummers LK: Scleromyxedema. A case series highlighting long-term outcomes of treatment with intravenous immunoglobulin (IVIG). Medicine 2008;87:10-20.

-10 Caradonna S, Jacobe H: Thalidomide as a potential treatment for scleromyxedema. Arch Dermatol 2004;140:277-280.

11 Kulczycki A, Nelson M, Eisen A, Heffernan M: Scleromyxoedema: treatment of cutaneous and systemic manifestations with high-dose intravenous immunoglobulin. Br J Dermatol 2003;149:1276-1281.

12 Gabriel SE, Perry HO, Oleson GB, Bowles CA: Scleromyxedema: a scleroderma-like disorder with systemic manifestations. Medicine 1988;67:58-65.

$\$ 13$ Wojas-Pelc A, Blaszczyk M, Glińska M, Jablońska S: Tumorous variant of scleromyxedema. Successful therapy with intravenous immunoglobulins. J Eur Acad Dermatol Venereol 2005;19:462-465.

$\$ 14$ Manousaridis I, Loeser C, Goerdt S, Hassel JC: Managing scleromyxedema with intravenous immunoglobulin: acute worsening of scleromyxedema with biclonal gammopathy. Acta Dermatoven APA 2010;19:15-19.

-15 Kreuter A, Stücker M, Kolios AGA, Altmeyer P, Möllenhoff K: Skleromyxödem. Eine chronisch progressive Systemerkrankung. Z Rheumatol 2012;71:504-514.

-16 Hill TG, Crawford JN, Rogers CC: Successful management of lichen myxedematosus. Arch Dermatol 1976;112:67-69.

17 Davis ML, Bartley GB, Gibson LE, Maguire LJ: Ophthalmic findings in scleromyxedema. Ophthalmology 1994;101:252-255.

18 Allen PW, Dymock RB, MacCormac LB: Superficial angiomyxomas with and without epithelial components. Report of 30 tumors in 28 patients. Am J Surg Pathol 1988;12:519-530.

$\$ 19$ Calonje E, Guerin D, McCormick D, Fletcher CD: Superficial angiomyxoma: clinicopathologic analysis of a series of distinctive but poorly recognized cutaneous tumors with tendency for recurrence. Am J Surg Pathol 1999;23:910-917.

20 Allam M, Ghozzi M: Scleromyxedema: a case report and review of the literature. Case Rep Dermatol 2013;5:168-175.

21 Sansbury JC, Cocuroccia B, Jorizzo JL, Gubinelli E, Gisondi P, Girolomoni G: Treatment of recalcitrant scleromyxedema with thalidomide in 3 patients. J Am Acad Dermatol 2004;51:126-131. 
Dolenc-Voljč et al.: Scleromyxedema with Subcutaneous Nodules: Successful Treatment with Thalidomide and Intravenous Immunoglobulin

22 Migkou M, Gkotzamanidou M, Terpos E, Dimopoulos MA, Kastritis E: Response to bertezomib of a patient with scleromyxedema refractory to other therapies. Leuk Res 2011;35:209-211.

23 Bidier M, Zschoche C, Gholam P, Enk AH, Hadaschick EN: Scleromyxoedema: clinical follow-up after successful treatment with high-dose immunoglobulins reveals different long-term outcomes. Acta Derm Venereol 2012;92:339-409.

24 Jacob SE, Fien S, Kerdel FA: Scleromyxedema, a positive effect with thalidomide. Dermatology 2006;213:150-152.

-25 Amini-Adle M, Thieulent N, Dalle S, Balme B, Thomas L: Scleromyxedema: successful treatment with thalidomide in two patients. Dermatology 2007;214:58-60.

-26 Efthimiou P, Blanco M: Intravenous gammaglobulin and thalidomide may be an effective therapeutic combination in refractory scleromyxedema. Case report and discussion of the literature. Semin Arthritis Rheum 2008;38:188-194.

27 Wright RC, Franco RS, Denton MD, Blaney DJ: Scleromyxedema. Arch Dermatol 1976;112:63-66.

Table 1. Overview of the use of IVIg, thalidomide and bortezomib in the treatment of scleromyxedema ${ }^{a}$

\begin{tabular}{|c|c|c|c|c|c|}
\hline Treatments & Dosage & Patients & Follow-up & Response assessment & References \\
\hline IVIgb & $2 \mathrm{~g} / \mathrm{kg}$ body weight/cycle & 27 & 2 months to 11 years & $\begin{array}{l}8 \text { - complete response } \\
14 \text { - partial response } \\
5 \text { - marked improvement }\end{array}$ & {$[7-9,11,14,23]$} \\
\hline IVIgc & $1.5 \mathrm{~g} / \mathrm{kg}$ body weight/cycle & 1 & 2 years & marked improvement & [13] \\
\hline Thalidomided $^{\mathrm{d}}$ & $100-400 \mathrm{mg} /$ day & 7 & 6 months to 2 years & $\begin{array}{l}5 \text { - marked improvement } \\
2 \text { - partial improvement }\end{array}$ & {$[10,21,24,25]$} \\
\hline $\begin{array}{l}\text { IVIg and } \\
\text { thalidomide }\end{array}$ & $\begin{array}{l}2 \mathrm{~g} / \mathrm{kg} \text { body weight/cycle (IVIg) } \\
50-150 \mathrm{mg} / \text { day (thalidomide) }\end{array}$ & 1 & 2 years & $\begin{array}{l}\text { significant improvement and } \\
\text { remission }\end{array}$ & {$[26]$} \\
\hline Bortezomib $^{f}$ & $1.0-1.3 \mathrm{mg} / \mathrm{m}^{2} /$ cycle & 1 & 2 years & $\begin{array}{l}\text { rapid improvement and almost } \\
\text { complete regression }\end{array}$ & {$[22]$} \\
\hline
\end{tabular}

a Treatment results are difficult to compare because of different treatment regimens, duration of treatment and follow-up of the patients. b Previous treatment with other drugs in 21 patients (corticosteroids, methotrexate, melphalan, cyclophosphamide, cyclosporine, mycophenolate mofetil, D-penicillamine, thalidomide, bortezomib, chloroquine, hydroxychloroquine, phototherapy, photopheresis, interferon, acitretin). Patients received from 1 to 32 cycles of IVIg [9]. . combination therapy with melphalan and corticosteroids. ${ }^{\mathrm{d}}$ Previous treatment with other drugs in all patients (melphalan, corticosteroids, cyclophosphamide, methotrexate, acitretin, photopheresis, chloraminophen). ${ }^{\mathrm{e}}$ Previous treatment with corticosteroids, cyclosporine and melphalan. ${ }^{\mathrm{f}}$ Combination therapy with dexamethasone. Previous treatment with methotrexate, melphalan, corticosteroids and lenalidomide.
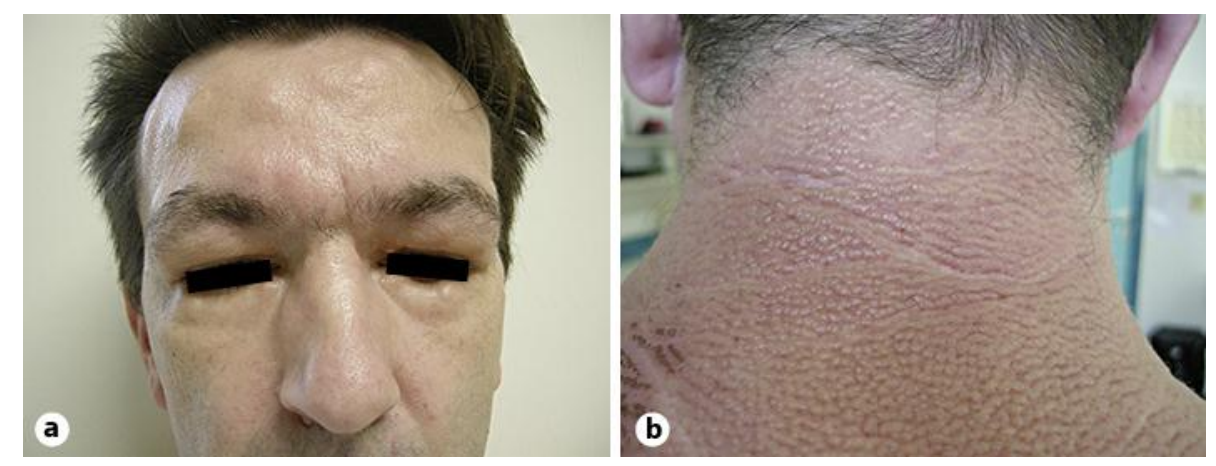

Fig. 1. Scleromyxedema: nodular lesions on the face (a) and papular mucinosis on the neck (b). 
Dolenc-Voljč et al.: Scleromyxedema with Subcutaneous Nodules: Successful Treatment with Thalidomide and Intravenous Immunoglobulin

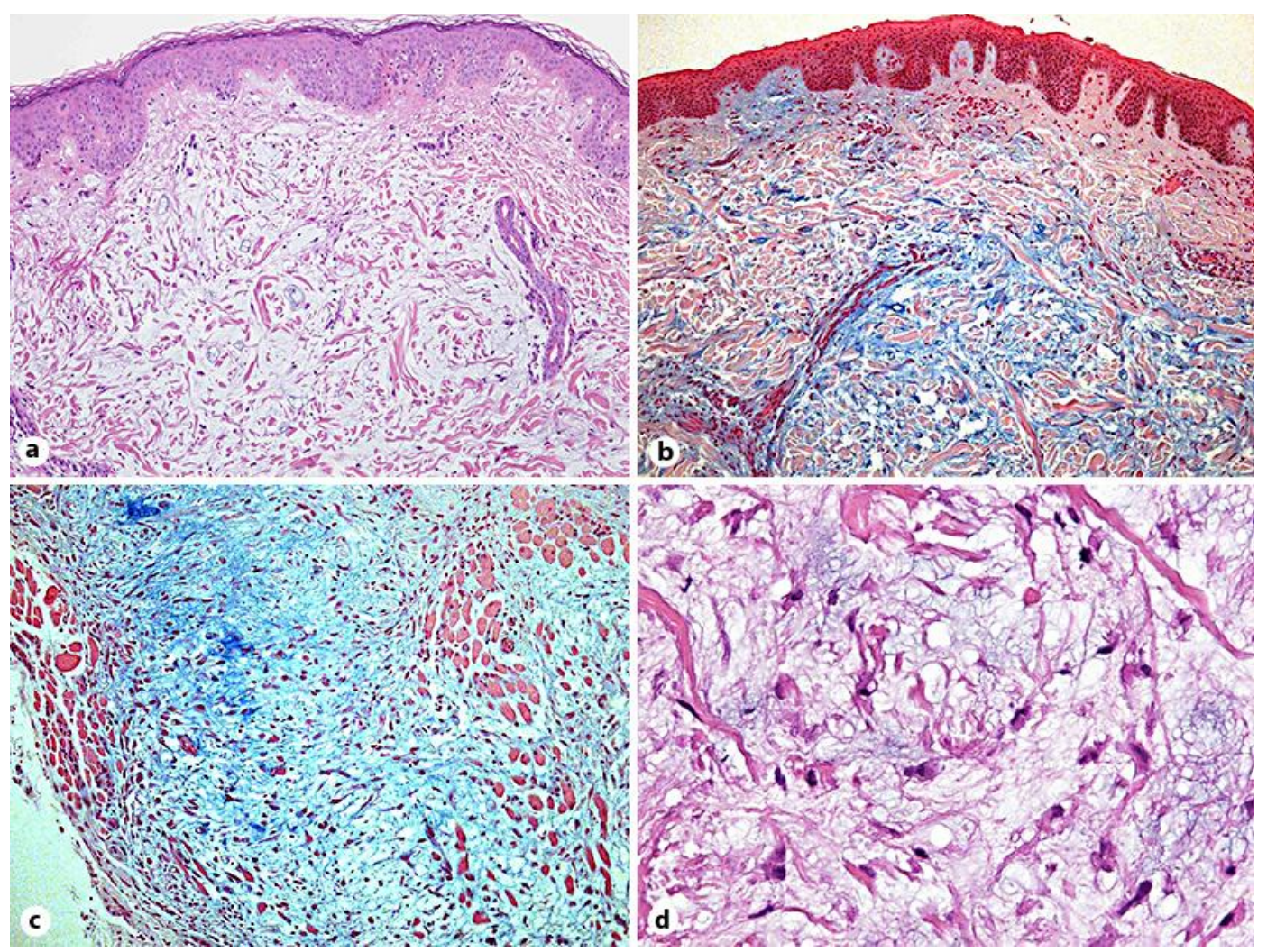

Fig. 2. Scleromyxedema: collagen fibers in the dermis are widely separated by mucin deposits (a, b). Nodular involvement of subcutaneous tissue (c). Fibroblasts are increased in number (d). Localization: trunk (a, b) and periorbital subcutaneous tissue (c, d). Stainings: HE (a, d) and Alcian blue (b, c).
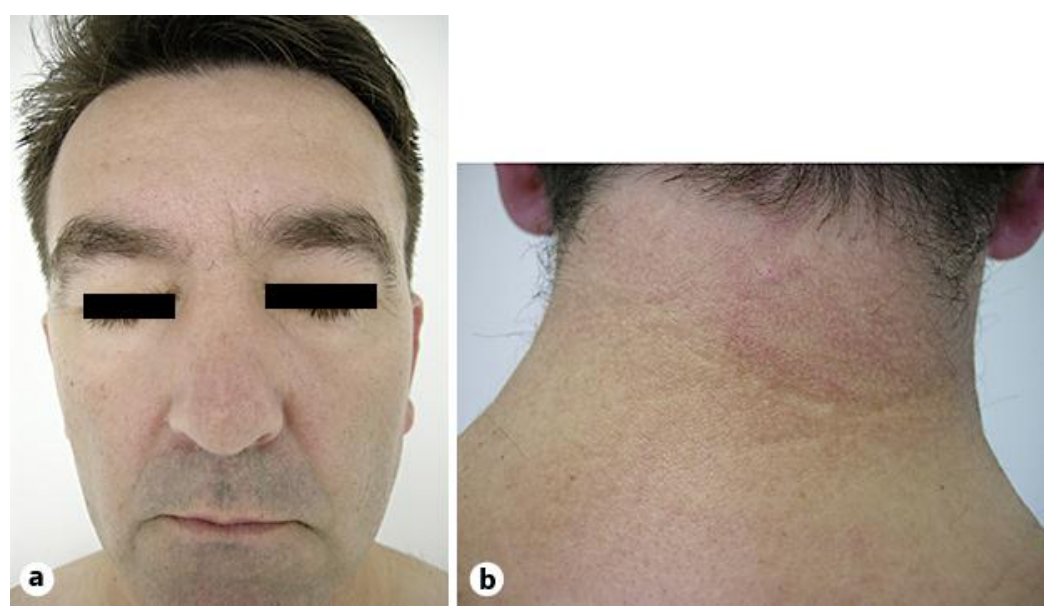

Fig. 3. Complete regression of nodular lesions on the face (a) and papular mucinosis on the neck (b). 